\title{
US experience with doctors and patients sharing clinical notes
}

The move to offer patients online access to their clinicians' notes is accelerating and holds promise of supporting more truly collaborative relationships between patients and clinicians, say Jan Walker, Michael Meltsner, and Tom Delbanco

\author{
Jan Walker assistant professor of medicine ${ }^{1}$, Michael Meltsner professor of law ${ }^{2}$, Tom Delbanco \\ professor of medicine ${ }^{1}$
}

'Division of General Medicine and Primary Care, Harvard Medical School, Beth Israel Deaconess Medical Center, Boston, MA 02215, USA; ${ }^{2}$ Northeastern University School of Law, Boston, USA

For decades clinicians have experimented with making medical records available to patients. ${ }^{1-6}$ Now electronic medical records and associated secure internet portals provide patients the opportunity to view test results, medications, and other selected parts of the medical record on line. ${ }^{7}$ But few patients are offered full access to their records; clinicians' notes are rarely visible. After a demonstration project showed the acceptability of OpenNotes (www.myopennotes.org) in the US, ${ }^{8}$ several prominent healthcare providers decided to make clinicians' notes available to patients online before further formal evaluation. We describe the OpenNotes movement in the US and how sharing notes with patients is spreading. We also underline the case for research to assess the long term effect of sharing notes and the potential to foster improved and truly collaborative care.

\section{US OpenNotes initiative}

The movement to share clinicians' notes with patients in the US was spurred by the findings of a demonstration and evaluation project that included 105 volunteering primary care doctors working at three large and disparate institutions and 19 000 of their patients who were registered to use their patient portal (box 1). ${ }^{8}$ Most patients in the study chose to read their notes and reported benefits from doing so, with only a slight effect on primary care doctors' workload. After 12 months, $99 \%$ of patients wanted to continue to have access to their notes online and none of the doctors decided to stop the practice.

In interviews, focus groups, and surveys, patients described how access to their notes gave them a new understanding of the importance of medications and more motivation to adhere to treatment. They reported that they were moved to change their behaviour after seeing words like "obese" in their notes. They reminded harried doctors about follow-up that had not been completed and shared the notes with family and caregivers when they could not remember the details of a visit. Elderly patients and those with little education were just as interested in reading their notes as young well educated people. ${ }^{9}$ In box $2 \mathrm{MM}$ describes his experience.

Based on these results, the participating institutions decided to expand OpenNotes throughout their ambulatory services, including specialty as well as primary care. At Beth Israel Deaconess Medical Center, a large Harvard teaching hospital, 85000 patients can now view their clinicians' notes online, 220 000 patients have access at Geisinger, an integrated health system in rural Pennsylvania, and 128000 patients in the University of Washington health system can review their notes. Other US providers have followed their lead, including the Mayo and Cleveland Clinics, Dartmouth-Hitchcock Medical Center, MD Anderson Cancer Hospital, Kaiser Permanente Northwest, and Group Health Cooperative. The national Veterans Administration (VA) system now offers fully open records at all its centres, and a recent survey completed by 6800 VA patients reaffirmed results from the initial OpenNotes study. ${ }^{10}$ The Boston Children's Hospital and Nationwide Children's Hospital in Ohio have opened notes to parents and guardians and are looking at independent access for adolescents. Sharing notes is not restricted to doctors. Most institutions open notes written by nurse practitioners and physician assistants, and some open those signed by other health professionals, such as clinical pharmacologists and occupational and physical therapists. Teaching institutions usually open notes written by registrars and fellows in the specialties, and by medical and nursing students. As part of the treatment process, some 


\section{Box 1: OpenNotes study}

12 month study in primary care practices at three sites

- Beth Israel Deaconess Medical Center, a large teaching hospital offering primary care in Boston, and affiliated suburban practices

- Geisinger Health System, an integrated system with clinics scattered through rural Pennsylvania

- Harborview Medical Center, a safety net hospital in the University of Washington health system in Seattle

\section{Participants}

- 105 primary care physicians completed the study; 143 declined to participate

- Physicians; notes were opened to $>19000$ patients who were registered for their institution's portal; patients were notified by secure portal message that their notes would be available during the study

- Participating doctors were allowed to exclude patients from the study; 1023 were excluded at Harborview (mainly patients with major mental illness or substance misuse), 158 were excluded at Beth Israel Deaconess, and 139 at Geisinger

\section{How it worked}

- After a visit, the doctor's electronic signature triggered a secure message notifying the patient the note was available

- The patient could log in to the institution's secure portal and read the note

- Before the next scheduled visit, another secure message encouraged the patient to review the note to prepare for the visit

- Notes written before the study were not available online

\section{Evaluation}

- Surveys of patients and doctors before and after the intervention

- Analysis of email volume and portal use

\section{Patient results}

- $>80 \%$ of patients opened at least one note

- Over two thirds reported better understanding of their health and medical conditions, taking better care of themselves, doing better with taking their medications, or feeling more in control of their care

- Few (1-8\% at the three sites) were confused, worried, or offended by what they read

- About $20 \%$ shared a note with someone else

- $>85 \%$ said availability of notes would influence future choice of providers

\section{Doctor results}

- Only $3 \%$ spent more time answering patient questions outside of visits, $11 \%$ spent more time writing or editing notes; email volume did not change

- About $20 \%$ reported changing the way they wrote about cancer, mental health, substance misuse, or obesity

\section{Box 2: Patient's perspective}

I was part of the original OpenNotes study so I have been reading my doctor's notes for five years. Reviewing, downloading, copying, or sharing a note in your medical records isn't a prescription. It's an option. I can access the information or not, read and respond, or simply take it in. What is important is that the notes written by medical staff are understandable to patients, accessible, and accurate.

When the practice was in an early testing phase I provided information to my primary care physician as he typed his notes; the conversation about the proper terms to describe my current health sharpened our mutual understanding of my condition. Later I shared the note with family and was able to answer their questions in a way that would have been impossible without the text before me. Clarity about drug doses almost certainly enhanced my adherence, and I was also able to have a longstanding reference to a drug allergy I did not have removed from my record-something I had failed to achieve before by speaking to healthcare support staff. Reading the notes-and in my case jointly creating them-levelled the playing field, facilitated questions and comments, and deepened my already strong sense of trust in my doctor. For notes written by specialists, I more often needed to clarify technical language by emailing questions. Several times I pointed out errors concerning my family history. Miscommunication between doctors and patients isn't going to end with open notes, but it will help, and I think it will encourage people to take more responsibility for their health. It has provided me with better information and greater confidence that my doctors and I are on more equal terms and on the same page.

I know that some patients worry about privacy, but particularly if we are ill, I think few would dispute that full communication among all interested parties is far more important than limiting access.

providers are also beginning to share notes written by specialists in mental disorders.

By December 2014, almost five million US patients had been provided with online access to their notes. Parallel developments in US health information technology have supported this spread, including government funding to increase use of electronic medical records. The Blue Button movement, initiated by the White House Presidential Innovation Fellows programme, encourages consumers to view and download their health information (http://healthit.gov/patients-families/your-healthdata) and products such as HealthVault, a free Microsoft service, enable people to aggregate their health data in one online location.

The OpenNotes movement has attracted extensive media coverage, including publication of personal stories about benefits to patients and debate about the impact on clinicians. ${ }^{11-13}$ The movement has also been endorsed by prominent clinical organisations, including the American College of Physicians, and by consumer organisations. ${ }^{14}{ }^{15}$ There is also a growing call by patients for access to records, and suppliers of electronic medical record software, such as Epic (www.epic.com), are starting to build open clinicians' notes into their products.

The US movement to share notes with patients is part of a global movement. Internationally there are many examples of initiatives enabling people to access their full medical records. Estonia launched a nationwide electronic record system in 2008 designed to include "transparent" access to doctors' notes. Since 2009, "all healthcare providers have an obligation to send [an] agreed number of standardized medical documents to the electronic health record." ${ }^{16}$ Taavi Lai, who was involved in developing 
the system, says there is "increasing pressure [from patients] to upload an increasing volume of data to the portal, as well as expressions of chagrin if a service provider/doctor/independent nurse practitioner doesn't do that quickly enough."

As part of the SUSTAINS project in Uppsala, Sweden, patients can access clinical notes in real time on a county-wide portal, even before doctors have signed them. The project's success is spawning pressure to expand nationwide. In the UK, several practices and some hospital units are opening notes to patients; an initiative by one primary care group, Haughton Thornley Medical Centres, invites patients to view their records once they complete an explicit consent process to assume "shared responsibility." And the NHS has re-emphasised its desire to promote access to medical and social care records, including the ability to share them with care givers and others that patients nominate. ${ }^{17}$

\section{Benefits outweigh risks}

Doctors' understanding of the benefits for patients is growing. We know that memory for what happens and what is said in consultations is often fleeting or distorted, and that

knowledgeable and actively engaged patients may have better outcomes. ${ }^{18}{ }^{19}$ But doctors worry that they may have to spend additional time carefully composing each note, that they will face an avalanche of subsequent questions, or that they will need to deal with requests for trivial changes to their notes. ${ }^{9}$ They also fear that patients will be alarmed and worried by what they read and that "watering down" medical language will undermine efficient communication between clinicians. We heard these concerns from doctors we approached in 2010 to join the OpenNotes study, and in spite of ongoing findings showing minimal effect on the participating doctors, we hear the same concerns today.

Further research is needed; many doctors tell us they want evidence about the effect of open notes on clinical outcomes. This is methodologically challenging; opening notes has a wide range of possible effects, and they will be difficult to isolate. Little is known about the long term effects of open notes, but our observation of implementations by multiple providers shows that clinicians adapt readily, and once open notes are switched on, few express ongoing misgivings. We have no reports of doctors turning back from sharing notes once they have started.

Some providers allow clinicians to exclude selected patients or hide selected notes, and many initially excluded notes written by psychotherapists and specialists in mental disorders. ${ }^{20}$ Early reports suggest that patients continue to read notes rather than just looking at them once out of curiosity, and that the rate of "hiding" notes declines as doctors gain experience with opening them to patients (unpublished data). Kaiser Permanente Northwest monitored email traffic between patients and clinicians for the first three months and found no change in volume (Monica Seidel, personal communication), echoing findings from the original OpenNotes study. ${ }^{8}$

\section{Looking to the future}

Face validity and growing evidence has convinced early adopters to embed open clinical notes into primary and outpatient specialty care. Although our experience suggests that open notes quickly becomes standard practice and requires little further attention, more evidence is needed to confirm whether transparent records help patients follow agreed care plans, medication regimens, preventive measures, or lifestyle changes. Do they respond more appropriately to referrals for tests and specialist care? As people gain better understanding of their condition, do open notes reduce or fuel their demand for investigations? How often are mistakes in documentation identified and corrected? Are there fewer missed appointments or fewer requests to be seen by a doctor? Are providers spurred to write more clearly or accurately? Does clinically important communication and trust between patients and clinicians increase?

Open notes also provide a platform for further interventions. Emerging technologies will explain arcane medical language, link to educational interventions, and help those with poor health literacy. And inviting patients to coauthor notes-essentially turning open notes into our notes-could enhance agreement on clinical priorities, reinforce patient engagement, and perhaps off-load some work from overburdened clinicians. Finally, full transparency will help clarify who will control the next generations of medical records. As providers consider what and what not to include, patients too will make choices. ${ }^{21}$

We expect fully open records to foster truly collaborative patient-clinician relationships. The variety of institutions, doctors, and patients taking up this practice suggests it is a concept widely applicable to healthcare. Though evidence is incomplete, there is already a compelling case for further implementation and exploration.

\section{We thank Melissa Anselmo for her help.}

Contributors and sources: TD and JW led the article's discussion of the clinician, organizational, and policy perspectives. MM is one of 10000 patients who participated in the original OpenNotes study; he contributed the patient's perspective and collaborated in other aspects of the manuscript. JW is the guarantor.

Funding: This work was supported primarily by the Robert Wood Johnson Foundation, the Drane Family Fund, John and Marilyn Keane, the Richard and Florence Koplow Charitable Foundation, and the $\mathrm{Dr}$ An and Lorraine $\mathrm{C}$ Wang Foundation.

Competing interests: We have read and understood BMJ policy on declaration of interests and declare TD and JW are the creators and leaders of OpenNotes. TD holds stock options in Eliza Corp.

Provenance and peer review: Commissioned; not externally peer reviewed.

Baldry M, Cheal C, Fisher B, Gillett M, Huet V. Giving patients their own records in general practice: Experience of patients and staff. BMJ 1986-292:596-8.

2 McFarlane WJ, Bowman RG, Maclnnes M. Patient access to hospital records: a pilot project. Can J Psychiatry 1980;25:497-502.

3 Homer CS, Davis GK, Everitt LS. The introduction of a woman-held record into a hospital antenatal clinic: the bring your own records study. Aust N Z J Obstet Gynaecol 1999;39:54-7.

4 Earnest MA, Ross SE, Wittevrongel L, Moore LA, Lin CT. Use of a patient-accessible electronic medical record in a practice for congestive heart failure: Patient and physician experiences. J Am Med Inform Assoc 2004;11:410-7.

5 Hannan A. Providing patients online access to their primary care computerised medical records: A case study of sharing and caring. Inform Prim Care 2010;18:41-9.

6 Golodetz A, Ruess J, Milhous RL. The right to know: giving the patient his medical record. Arch Phys Med Rehabil 1976;57:78-81.

7 Reti SR, Feldman HJ, Safran C. Governance for personal health records. J Am Med Reti SR, Feldman HJ, Safran
Inform Assoc 2009;16:14-7.

8 Delbanco T, Walker J, Bell SK, Darer JD, Elmore JG, Farag N, et al. Inviting patients to read their doctors' notes: a quasi-experimental study and a look ahead. Ann Intern Med 2012:157:461-70.

9 Walker J, Leveille SG, Ngo L, Vodicka E, Darer JD, Dhanireddy S, et al. Inviting patients to read their doctors' notes: patients and doctors look ahead. Ann Intern Med 2011;155:811-9.

10 Nazi KM, Turvey CL, Klein DM, Hogan TP, Woods SS. VA OpenNotes: exploring the experiences of early patient adopters with access to clinical notes. J Am Med Inform Assoc 2014 Oct 29 [Epub ahead of print].

11 Wielawski I. OpenNotes: putting medical record transparency to the test. In: Isaacs SL, Colby DC, eds. To improve health and health care. Vol XVI. Robert Wood Johnson Foundation, Jossey-Bass, 2014.

12 Elias P. A physician responds to OpenNotes critics. KevinMD 2014 July 31. www.kevinmd. com/blog/2014/07/physician-responds-opennotes-critics.html.

13 Shyder G. The promise and peril of OpenNotes. KevinMD 2014 May 1. www.kevinmd. com/blog/2014/05/promise-peril-opennotes.html. 


\section{Big bang versus an incremental change}

Some providers have taken a "big bang" approach. Others have rolled out open notes sequentially as individual clinicians and departments decide to participate. Some have done "quiet" implementation with minimal communications or fanfare. Others prefaced patient access to notes with announcements in local media, informed patients through multiple channels, conducted portal registration campaigns, and used automated email messages to invite patients to read each new note as it is made available.

Most doctors want to understand how open notes will work, but beyond suggestions for ways to manage potentially sensitive or obscure terms few seem to want much teaching about it.

14 Kuhn T Basch B, Barr M, Yackel T. Clinical documentation in the 21st century: executive summary of a policy position paper from the American College of Physicians. Ann Intern Med 2015 Jan 13. [Epub ahead of print.]

15 Guest JA, Quincy L. Consumers gaining ground in health care. JAMA 2013;310:1939-40.

16 Tiik M, Ross P. Patient opportunities in the estonian electronic health record system. In: Bos L, Blobel B, Benton S, Carroll D, eds. Medical and care compunetics 6. IOS Press, 2010:171.

17 NHS. Five year forward view. 2014. www.england.nhs.uk/wp-content/uploads/2014/10/ 5yfv-web.pdf.

18 Kessels RP. Patients' memory for medical information. J R Soc Med 2003;96:219-22.
19 Hibbard JH, Mahoney ER, Stock R, Tusler M. Do increases in patient activation result in improved self-management behaviors? Health Serv Res 2007;42:1443-63.

20 Kahn MW, Bell SK, Walker J, Delbanco T. Let's show patients their mental health records. JAMA 2014:311:1291-2.

21 Tierney WM, Alpert SA, Byrket A, Caine K, Leventhal JC, Meslin EM, et al. Provider responses to patients controlling access to their electronic health records: a prospective cohort study in primary care. J Gen Intern Med 2015;30(suppl 1):31-7.

Cite this as: BMJ 2015;350:g7785

(c) BMJ Publishing Group Ltd 2015 